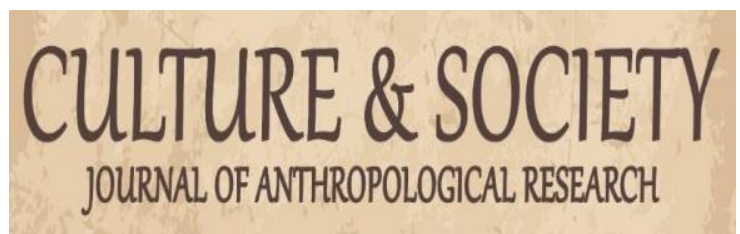

Culture \& Society: Journal of Anthropological Research

VOL. 1 NO. 1 SEPTEMBER 2019

http://culture.ppj.unp.ac.id

Email: culture@ppj.unp.ac.id

ISSN: 2686-343X (E-ISSN) 2686-3421 (P-ISSN)

DOI: https://doi.org/10.24036/culture/vol1-iss1/5

\title{
Bentuk Aktivitas Partisipasi Mahasiswa Dalam Mengikuti Kegiatan Sosial (Studi Kasus: Mahasiswa Anggota Organisasi Volunteer Active Padang)
}

\author{
Zaitun Munirah ${ }^{1}$, Erianjoni Erianjoni ${ }^{2}$ \\ ${ }^{1,2}$ Universitas Negeri Padang \\ Email: zaitun.munirah97@gmail.com, erianjonisosiologi@gmail.com
}

\begin{abstract}
Abstrak
Penelitian ini dilakukan dengan tujuan menjelaskan bagaimana bentuk partisipasi aktif mahasiswa dalam mengikuti kegiatan sosial di organisasi volunteer ACTIVE Padang. Dianalisis menggunakan teori tindakan sosial yang dikemukakan oleh Max Weber. Pendekatan yang digunakan adalah metode penelitian kualitatif yang mencari makna, pemahaman, pengertian tentang suatu fenomena. Data yang diperolah dari penelitian kualitatif bersifat deskriptif yang mendetail dari suatu kasus yang diteliti. Tipe ini merupakan tipe yang memperhatikan semua aspek, lebih tepatnya dengan melihat bagaimana partisipasi mahasiswa dalam kegiatan sosial yang dilaksanakan di organisasi volunteer ACTIVE. Teknik purposive sampling yang digunakan dengan dasar pertimbangan memilih kriteria informan yang dibutuhkan terlebih dulu, yaitu para anggota yang masih berstatus mahasiswa aktif serta merupakan anggota organisasi ACTIVE. Bentuk observasi yang digunakan ialah jenis participant observer. Kemudian Wawancara dilakukan oleh peneliti terhadap informan yang telah ditentukan dari awal dan dilakukan secara langsung terhadapa informan. Studi dokumentasi memperoleh data pendukung yang di cari berkaitan erat dengan fokus penelitian. Hasil dari penelitian ini yaitu menujukan bentuk partisipasi mahasiswa dalam kegiatan sosial terlihat dari setiap program kegiatan yang dilaksanakan oleh organisasi ACTIVE, yaitu: kegiatan pengajaran, kelas motivasi, belanja bersama anak panti, kegiatan rekreasi. Setiap kegiatan tersebut menujukkan bentuk partisipasi aktif dari mahasiswa.
\end{abstract}

Kata Kunci: Mahasiswa, Partisipasi, Kegiatan Sosial

\section{Abstract}

This research was conducted with the aim of explaining how active student participation is in participating in social activities in Padang ACTIVE volunteer organizations. Analyzed using social action theory proposed by Max Weber. Suggestions used are qualitative research methods that look for meaning, understanding, understanding of phenomena. Data obtained from descriptive qualitative research in detail from a case offered. This type is a type that pays attention to all aspects, further by looking at how students participate in social activities carried out in ACTIVE voluntary organizations. The purposive sampling technique used was based on the consideration of selecting the criteria for the informants needed first, namely the members who were still active students and were members of the ACTIVE organization. The observation used is the type of participant observer. Then the interview was conducted by the researcher with the informant who had been determined from the beginning and conducted directly with the informant. Study Gets Opinions that support in research related to the focus of research. ACTIVE, namely: consulting activities, motivational classes, shopping with orphans, recreation activities. Each of these activities shows a form of active participation from students.

Keywords: College student, Participation, Social activitie

\begin{tabular}{l|l|l} 
Received: August 29, 2019 & Revised: September 4, 2019 & Published: September 6, 2019
\end{tabular}

Culture \& Society: Journal of Anthropological Research Vol. 1, No. 1, Th. 2019 
Mahasiswa dalam peraturan pemerintah RI No.30 tahun 1990 adalah peserta didik yang terdaftar dan belajar di perguruan tinggi tertentu (Nasional et al., 1990). Mahasiswa juga seseorang yang sedang dalam periode pertumbuhan remaja akhir menuju masa dewasa. Masa yang ditandai dengan kematangan akal, jasmani, dan perasaan merupakan masa yang optimal yang dimiliki oleh mahasiswa (Ahmad, 2009). Dalam mencapai tahap itu, dibutuhkan persiapan dalam berfikir kritis. Kemampuan dalam memecahkan masalah yang merupakan karakteristik orang dewasa. Hal ini juga dapat menentukan tingkat nilai mahasiswa itu sendiri, yaitu dengan melihat tingkat intelektualitas tinggi, kecerdasan dalam berfikir dan kerencanaan dalam bertindak (Basir, 2011). Selain itu mahasiswa juga dituntut bersifat kreatif serta bertindak dengan cepat dan tepat. Oleh Karena itu mahasiswa mempunyai potensi yang lebih dibandingkan kelompok masyarakat lainnya (Hanurawan, 2012). Baik buruknya nasib masa depan bangsa ditentukan oleh kondisi pemuda dan mahasiswa masa sekarang ini. Kecakapan hidup tersebut dapat dikembangkan dalam perguruan tinggi. Mahasiswa yang memiliki kecakapan tersebut memiliki penalaran yang lebih terhadap lingkungan sekitarnya. Mahasiswa umumnya memiliki aktivitas rutin yang dilakukan dalam lingkungan kampus. Selain itu, juga butuh beraktivitas di luar ruang lingkup akademisnya (Diani, 2017). Dengan mengikuti organisasi yang dilakukan baik di dalam lingkungan kampus maupun lingkup masyarakat. Untuk lingkup perkuliahan sendiri, hanya terdapat sebuah organisasi yang bersifat kemahasiswaan antar kampus. Organisasi kemahasiswaan antar kampus merupakan organisasi mahasiswa yang memiliki kedudukan resmi di lingkungan kampus dan mendapatkan pendanaan, baik secara resmi maupun melalui sponsor dalam setiap pelaksanaan kegiatan kemahasiswaan dari kampus (Dwi Yanika Hesti Nugraha, 2011).

Partisipasi dari mahasiswa dalam setiap kegiatan di luar kegiatan akademisnya ialah untuk melihat arti dari kualitas hidupnya di lingkungan masyarakat. Dengan menjadi pribadi yang mampu mengabdi terhadap masyarakat (Astuti, 2008). Sehingga mampu menalar dan memberikan alternatif pemecah permasalahan serta mampu mengembangkan sikap kritis tersebut dilingkungannya masing-masing. Pemberdayaan yang dilakukan pada masyarakat adalah sebuah konsep pembangunan ekonomi yang merangkum nilai-nilai sosial (Purbathin, 2010). Ketidakberdayaan dari masyarakat secara sosial dan ekonomi menjadi salah satu penghalang bagi masyarakat untuk dapat berhasil bangkit dari keterpurukannya (Widjajanti, 2011). Kontribusi mahasiswa yang ikut melaksanakan kegiatan sosial yang didasarkan pada permasalahan yang terdapat di lingkungan sekitar mereka, kemudian berusaha untuk menjadi bagian penyelasainnya (Humaida, 2016). Bentuk kegiatan sosial lain muncul dengan organisasi yang berada di luar lingkungan kampus. Bergerak dari latar belakang yang beragam, seperti membantu memberikan motivasi, berbagi ilmu pengetahuan dan lain sebagainya. Organisasi yang melakukan kegiatan sosial mengemban tujuan untuk berbagi dan membantu meningkatkan kualitas pendidikan bangsa. Karena melihat masih banyaknya permasalahan-permasalahan yang ada di sekitar lingkungan kita. Seperti permasalahan rendahnya sarana dan pra-sarana, rendahnya kualitas guru, rendahnya kesejahteraan guru, rendahnya prestasi siswa, rendahnya kesempatan pemerataan pendidikan, rendahnya relevansi pendidikan dengan kebutuhan, dan mahalnya biaya pendidikan. Hal seperti inilah yang menjadi penyebab rendahnya kualitas pendidikan yang berujung terhambatnya penyediaan sumber daya menusia dengan keahlian serta keterampilan untuk memenuhi pembangunan bangsa dalam berbagai bidang.

Diantaranya organisasi sukarelawan yang diberi nama Action Time Volunteer atau disingkat menjadi ACTIVE yang terdapat di Padang. Dengan tujuan awal organisasi ini dibentuk yaitu menjadi sebuah lembaga yang mencerdaskan spiritual, emosional dan intelektual anak usia sekolah yang kurang beruntung secara finasial secara sukarela. Organisasi ini berdiri pada tanggal 20 September 2015 oleh pendirinya ialah Melqi Hamdani pemuda asal Sumatera Barat yang kini tengah menempuh pendidikan jenjang Doktoral di Australia. Organisasi ini beralamat di Jalan Limau Bali No. 10 J Lapai, Padang, Sumatera Barat. Bersifat independen dan berada di

\section{Culture \& Society: Journal of Anthropological Research Vol. 1, No. 1, Th. 2019}


bawah naungan lembaga Time Languange Centre. Ruang lingkup kegiatan organisasi ini ialah pada bidang sosial kemasyarakatan dan pendidikan. Setiap organisasi memiliki tanggung jawab lingkungan san sosial, karena lingkungan masyarakat juga merupakan bagian dari para pemangku kepentingan (Adhitya, 2016). Sasaran kegiatan organisasi ini berupa anak-anak panti asuhan, dan saat ini sasaran kegiatan mengajar organisasi dilakukan pada lima panti asuhan yang terdapat di kota Padang, yaitu: (1) Panti Asuhan Al-Falah di Parupuk Tabing, (2) Panti Asuhan Al-Ihsan di Lapai, (3) Panti Asuhan Darul Ma'rif di daerah Nanggalo, (4) Panti Asuhan Nur Ilahi di Kurao Pagang, (5) Panti Asuhan Aisyiyah di Gunung Pangilun Kota Padang. Berikut data jumlah anak-anak pada setiap panti asuhan yang diikuti ACTIVE, yaitu sebagai berikut:

Tabel 1. Data Jumlah Anak di Panti Asuhan yang Dinaungi ACTIVE

\begin{tabular}{clcc} 
No & \multicolumn{1}{c}{ Nama Panti Asuhan } & Perempuan & Laki-laki \\
\hline 1. & Al-Falah & 20 & 15 \\
\hline 2. & Darul Ma'arif & 25 & 13 \\
\hline 3. & Aisiyah & 24 & 8 \\
\hline 4. & Al-Insan & 21 & 13 \\
\hline 5. & Nur Ilahi & 17 & 20 \\
\hline \multicolumn{2}{c}{ Jumlah } & $\mathbf{1 0 7}$ & $\mathbf{6 9}$ \\
\hline \multicolumn{2}{c}{ Total } & $\mathbf{1 7 9}$ \\
\hline
\end{tabular}

Dari tabel di atas, menjelaskan jumlah dari anak-anak panti yang terdapat pada masingmasing pantinya. Di Panti Al-Falah terdapat 20 anak perempuan dan 15 orang anak laki-laki, dengan jumlah total sebanyak 35 anak. Di Panti Darul Ma'arif terdapat 25 anak perempuan dan 13 anak laki-laki, dengan total 38 anak. Kemudian dari Panti Aisiyah terdapat 24 anak perempuan dan 8 anak laki-laki, dengan jumlah total 32 anak. Selanjutnya di Panti Al-insan dengan jumlah 21 anak perempuan dan 13 anak laki-laki, dengan jumlah total 34 anak. Kemudian yang terakhir, yaitu Panti Nur Ilahi dengan jumlah anak perempuan sebanyak 17 orang dan 20 orang anak laki-laki, dengan jumlah total sebanyak 37 orang. Dengan jumlah total secara keseluruhan sebanyak 179 anak dari 5 panti asuhan yang menjadi tempat ACTIVE melaksanakan kegiatan sosial bersama para anggota volunteer. Data diperoleh dari dokumen milik ACTIVE yang sudah di perbaharui oleh sekretaris ACTIVE sendiri. Sehingga data tersebut merupakan data yang terbaru dan relevan.

Hampir semua kalangan boleh bergabung ke dalam organisasi ini. Namun, terdapat kalangan yang mendominasi sebagai anggota, yaitu dari kalangan mahasiswa-mahasiswa yang sedang menempuh pendidikan di Kota Padang. Mahasiswa yang bergabung di dalamnya berasal dari latar belakang yeng beragam, seperti usia, asal daerah, organisasi yang diikuti, serta asal universitas. Tidak ada komunitas ataupun anggota dari organisasi lain yang mendominasi. Keanggotaan benar-benar luas tidak ada batasan mahasiswa dari golongan tertentu. Keterlibatan mahasiswa dalam kegiatan sosial memiliki hubungan positif dengan kesejahteraan subjektif (Utami, 2009). Mahasiswa yang memilih ikut melakukan kegiatan sosial memiliki alasan tersendiri yang melatarbelakanginya. Seperti seorang mahasiswa dari Universitas Andalas dan berdomisili di Kota Padang, bernama Rifqi Wildan Putra (22 tahun) yang memilih bergabung dengan ACTIVE karena alasan kemanusian dan ingin berbagi ilmu serta pengalaman dengan sesama anak panti asuhan yang membutuhkan.

Pada masa pengrekrutan anggota baru tanggal 15-31 Januari 2019, terdapat lonjakan pada jumlah anggota baru dan didominasi oleh mahasiswa. Hal ini dapat dilihat dari dokumen resmi organisasi yang mencatat jumlah anggota pertama ketika ACTIVE berjumlah 9 orang, tidak ada tahap pengrekrutan khusus saat itu. Anggotanya juga sudah saling mengenal sebelumnya, hanya dari lingkungan pertemanan sesama mahasiswa kemudian menyatakan kebersediaan dan berkomitmen kepada pendiri organisasi untuk bergabung. Kemudian tahun berikutnya, yaitu 2016 baru dilakukan penerimaan anggota baru sehingga terdapat sebanyak 21 orang yang

Culture \& Society: Journal of Anthropological Research Vol. 1, No. 1, Th. 2019 
tertarik dan bergabung kemudian tahun 2017 berjumlah 30 orang dan tahun berikutnya 2018 sebanyak 105 orang. Kemudian yang terakhir tahun 2019 sebanyak 122 orang. Angka ini jauh lebih tinggi dibandingkan tahun-tahun sebelumnya. Jumlah anggota organisasi terus bertambah setiap tahunnya.

Mahasiswa yang kini menjadi anggota terdiri dari universitas yang berbeda. Tepatnya terdapat 1 mahasiswa asal Universitas Dharma Andalas, 1 asal STKIP Adzkia, 2 asal UIN Imam Bonjol, 2 asal STBA Prayoga, 2 dari UBH, 3 asal UPI YPTK, 5 dari UNAND, kemudian jumlah terbanyak oleh UNP sebanyak 121 orang. Jumlah ini belum termasuk 15 anggota lama yang masih aktif dan berstatus mahasiswa. Berikut merupakan data jumlah anggota ACTIVE, yang sudah disederhanakan dan dibagi berdasarkan universitas asal, yaitu sebagai berikut:

Tabel. 2 Data Jumlah Anggota ACTIVE

\begin{tabular}{clccc}
\hline No & \multicolumn{1}{c}{ Asal Universitas } & Aktif & Pasif & Jumlah \\
\hline 1 & Universitas Negeri Padang & 53 & 68 & 121 \\
\hline 2 & Universitas Andalas & 3 & 2 & 5 \\
\hline 3 & Universitas Putra Indonesia YPTK & 1 & 2 & 3 \\
\hline 4 & $\begin{array}{l}\text { Universitas Islam Negeri Imam } \\
\text { Bonjol }\end{array}$ & 1 & 1 & 2 \\
\hline 5 & Universita Bung Hatta & 1 & 1 & 2 \\
\hline 6 & STBA Prayoga & 2 & - & 2 \\
\hline 7 & STKIP Adzkia & 1 & - & 1 \\
\hline 8 & Universitas Dharma Andalas & - & 1 & 1 \\
\hline Jumlah & & & $\mathbf{1 3 7}$ \\
\hline
\end{tabular}

Sumber: Dokumen oleh ACTIVE 2019

Berdasarkan tabel di atas, terdapat keterangan anggota yang aktif dan pasif dalam setiap kegiatan sosial yang dilaksanakan berdasarkan pembagian dari universitas asalnya. Di mana pada tabel juga memperliatkan jumlah dari anggota dari setiap universitas. Jumlah terbesar terdapat pada UNP yaitu sebanyak 121 orang, dengan 53 anggota aktif dan 68 yang pasif. Kemudian 5 anggota yang berasal dari UNAND, dimana 3 anggotanya dinilai aktif, dan lainnya pasif. Selanjutnya tedapat 3 anggota dari UPI YPTK, dengan 1 orang yang aktif dan 2 orang lainnya pasif. 2 Kemudian anggota asal UIN Imam Bonjol yang berjumlah 2 orang dengan 1 orang aktif dan 1 orang lainnya pasif. Jumlah yang sama persis dengan anggota dari UBH. Lalu, dari STBA Prayoga yang berjumlah 2 orang dan keduanya juga aktif. Selain itu terdapat 1 orang anggota asal STKIP Adzkia yang aktif dan 1 orang anggota dari Universitas Dharma Andalas yang terhitung pasif di organisasi.

Besarnya antusias mahasiswa untuk berpartisipasi dalam kegiatan sosial di masyarakat menjadi alasan peneliti memfokuskan pembahasan pada partisipasi mahasiwa di kota Padang dalam kegiatan sosial yang dinaungi oleh organisasi ACTIVE.Peneliti membatasi penelitian ini pada partisipasi mahasiswa mengikuti kegiatan sosial di dalam organisasi ACTIVE Padang. Kegiatan sosial dapat dilakukan oleh siapa saja tidak harus melihat usia atau latar belakang lainnya dan dilakukan secara sukarela di panti asuhan. Memiliki anggota yang didominasi oleh para mahasiswa yang menempuh pendidikan di Kota Padang. Oleh karena itu, adapun rumusan masalah dari penelitian ini ialah: Bagaimana bentuk partisipasi aktif mahasiswa anggota organisasi ACTIVE Padang?

\section{Metode Penelitian}

Pendekatan yang digunakan adalah metode penelitian kualitatif yang mencari makna, pemahaman, pengertian tentang suatu fenomena. Dapat dikatakan bahwa penelitian kualitatif, merupakan suatu proses penemuan dan pengumpulan, analisis, interprestasi data visual dan naratif yang komprehensif untuk mendapatkan pemahaman tentang suatu fenomena atau masalah yang menarik perhatian (Yusuf, 2014). Data yang diperolah dari penelitian kualitatif 
bersifat deskriptif yang mendetail. dari suatu kasus yang diteliti. Objek yang diteliti dapat berupa satu orang Tipe penelitian ialah studi kasus tepatnya melihat bagaimana partisipasi mahasiswa dalam organisasi volunteer ACTIVE.

Teknik pemilihan informan yang digunakan adalah teknik purposive sampling. Peneliti perlu memprediksi pengambilan sampel secara purposive yang dijadikan dasar dalam penentuan latar yang digunakan (Basrowi dan Suwandi, 2008). Oleh karena itu penelitian ini memiliki informan dengan pertimbangan khusus, yaitu para anggota yang masih berstatus mahasiswa aktif di Universitas Kota Padang, serta merupakan anggota organisasi ACTIVE yang memang aktif mengajar. Penentuan informan penelitian dalam penelitian kualitatif bukan pada jumlah informannya, melainkan pada penentuan sumber informasinya. Karena teknik purposive didasari dengan pertimbangan kriteria informan yang dibutuhkan dalam penelitian terlebih dulu (Arikunto, 2006).

Teknik selanjutnya melaksanakan observasi, yaitu dengan melakukan pengamatan secara langsung, kemudian dicatat sesuai dengan yang tampak pada objek yang diteliti (Sugiyono, 2012). Ketepataan hasil penelitian berasal dari peneliti itu sendiri. Dikarenakan peneliti yang memberi makna tentang apa yang diamatinya di lapangan dan bagaimana realitasnya (Margono, 2004). Dalam penelitian ini bentuk observasi yang digunakan ialah jenis participant observer, dimana peneliti berpartisipasi secara langsung, tidak hanya sekedar mengamati dari luar. Hal ini dikarenakan peneliti merupakan salah satu anggota organisasi ACTIVE sejak tahun 2015 hingga sekarang.

Setelah melakukan observasi penelitian dilanjutkan pada teknik wawancara. Dengan menggunakan pedoman wawancara agar penelitian ini tetap konsisten dengan persoalan yang akan ditanyakan dan fokus dari penelitian. Wawancara dilakukan oleh peneliti terhadap informan yang telah ditentukan dari awal dan dilakukan secara langsung terhadapa informan, yaitu anggota dari organisasi $A C T I V E$ yang masih berstatus mahasiswa di UNP, UNAND, DHARMA UNAND, UPI YPTK, UIN, UBH, STBA Prayoga, dan STKIP Adzkia. Melalui wawancara mendalam, peneliti mengumpulkan data dengan cara langsung tatap muka dengan informan yang telah dipilih sebelumnya.

Di samping itu, peneliti juga menggunakan studi dokumentasi. Di mana terdiri dari kutipan dokumen-dokumen yang diambil dengan cara mencatat dan mempertahankan konteks (Emzir, 2010). Dokumen merupakan sumber yang dapat memperkuat data yang telah didapat, dapat berbentuk bentuk teks tertulis, gambar, maupun foto. Bentuk data lainnya bisa tentang sekelompok orang, peristiwa atau kejadian yang terkait dengan fokus penelitian yaitu, partisipasi mahasiswa terhadap kegiatan sosial. Data dapat diperoleh dari organisasi ACTIVE yang berupa fhoto, catatan, baik itu dokumen resmi maupun pribadi yang berkaitan dengan mengenai kegiatan dari organisasi

\section{Hasil dan Pembahasan}

Organisasi ACTIVE dibentuk atas dasar rasa peduli terhadap lingkungan masyarakat, terutama dalam hal pendidikan. bersifat independen dan berada di bawah naungan lembaga Time Languange Centre atau disingkat dengan TIME. Berawal dari niat dari pendiri yang ingin mencoba memberikan bantuan kepada anak-anak yang kurang mampu. Seperti anak yang tinggal di panti asuhan yang serba kekurangan, tidak hanya dari segi finansial namun juga perhatian dan kasih sayang, karena mereka tumbuh di lingkungan tanpa keluarga yang utuh (Nisfil, 2015). Partisipasi yang dilakukan menyusun sebuah rencana program pembangunan yang dapat dan dianggap akan sangat dibutuhkan oleh masyarakat dalam meningkatkan kesejahteraannya (Mustanir, 2018). Melihat masih banyaknya siswa yang terkendala dengan sarana prasarana belajar yang berujung kepada kurangya minat siswa tersebut untuk belajar. Seperti buku dan alat-alat tulis dan lain sebagainya. Sehingga ACTIVE ingin memberikan peran disini, dengan membantu anak-anak yang masih berstatus siswa di panti asuhan dalam menghadapi kehidupan sekolah mereka. Dengan berusaha membantu terpenuhinya sarana dan prasarana belajar anak-anak usia sekolah yang terdapat di panti asuhan. penelitian ini bertujuan

\section{Culture \& Society: Journal of Anthropological Research Vol. 1, No. 1, Th. 2019}


menemukan partisipasi yang seperti apa yang dilakukan oleh mahasiswa yang menjadi anggota dari organisasi volunteer ACTIVE, yang didapatkan dengan melihat langsung bentuk kegiatan sosial yang dilaksanakan secara rutin oleh $A C T I V E$. Temuan yang diperoleh dalam penelitian ini ialah bentuk kegiatan sosial yang di dalamnya terdapat partisipasi aktif oleh mahasiswa anggota ACTIVE, yang diantaranya ialah:

\section{Kegiatan mengajar}

Dilaksanakan selama seminggu sekali dalam waktu dua jam sekali mengajar. Biasanya dilakukan pada hari sabtu atau minggu. Sistem pengajarannya tidak formal seperti sekolah pada umumnya. Lebih seperti pemantapan materi yang telah diperoleh anak-anak di sekolah. Sistem pengajaran dengan materi pembelajaran yang dibagi menjadi empat, yaitu: Matematika, IPA, IPS, Bahasa Inggris. Partisipasi mahsasiswa dalam kegiatan mengajar ini berupa sebagai pengajar yang mengajari pembelajaran sesuai dengan jurusan mahasiswa di universitasnya. Dengan demikian system kependidikan sebagai bagian yang tidak lepas dari proses pendidikan dengan keseluruhannya perlu mendapatkan perhatian yang utama (Muhson, 2009).

\section{Kegiatan kelas motivasi}

Kelas motivasi memang merupakan program baru. Dimulai dari tahun 2018 awal. Program ini dilaksanakan dalam waktu sebulan sekali. Biasanya dilakukan di panti asuhan tempat mengajar. Biasanya kelas motivasi ini diisi oleh para mahasiswa anggota volunteer yang membagi kisah pengalamannya. Namun, akhir-akhir ini kelas motivasi juga mengundang motivator dari luar. Partisipasi yang dilakukan mahasiswa dalam kegiatan ini, berupa kegiatan berbagi cerita pengalaman mereka ke anak-anak panti asuhan, dengan harapan dapat menginspirasi mereka dalam pertumbuhan menuju dewasa nantinya.

\section{Belanja bersama anak panti}

Kegiatan belanja bersama dilakukan secara rutin, namun dalam waktu-waktu terntentu. Misalnya pada saat bulan Ramadhan, ACTIVE mengadakan kegiatan belanja baju lebaran untuk anak-anak panti asuhan. Selain belanja baju Lebaran di bulan Ramadhan, setiap ajaran baru juga diadakan kegiatan belanja perlengakapan sekolah. Berikut gambar dari kegiatan belanja baju Lebaran dan juga kegiatan belanja alat tulis dengan anak-anak panti asuhan. Bentuk partispasi yang dilakukan oleh para mahasiswa anggota $A C T I V E$, berupa pendampingan anakanak panti yang ingin berbelanja di luar dan juga ikut berdonasi serta membantu menyebarkan pamflet iklan ajakan untuk berdonasi ke panti asuhan.

\section{Kegiatan rekreasi}

Kegiatan rekreasi yang dimaksud memang seperti kegiatan rekreasi pada umunya. Tidak ada aturan khusus, hanya kegiatan refreshing dengan mengajak ikut anak-anak panti main ke luar. Dengan begitu, mereka juga dapat merasakan kegiatan di luar panti layaknya anak-anak pada umunya. Bentuk partisipasi yang dilakukan mahasiswa dalam kegiatan ini yaitu, mendampingi anak-anak keluar dari panti dan bertanggungjawab terhadap keselamatan anak-anak yang dibawa main. Selain itu, mahasiswa anggota $A C T I V E$ juga ikut berdonasi untuk kegiatan ini yang dananya berasal dari uang kas organisasi yang dikumpulkan tiap minggu mengajar.

\section{Kesimpulan}

Partisipasi adalah peran serta seseorang atau kelompok masyarakat dalam proses pembangunan baik dalam bentuk pernyataan maupun dalam bentuk kegiatan dengan memberi masukan seperti: pikiran, tenaga, waktu, keahlian (skill), modal (materi), ikut memanfaatkan dan menikmati hasil-hasil pembangunan. Bentuk partisipasi yang dilakukan oleh mahasiswa yang menjadi anggota organisasi berupa, ikut serta dalam setiap kegiatan sosial yang dilaksanakan oleh $A C T I V E$. Bentuk kegiatan sosial yang didalamnya terdapat partisipasi aktif dari mahasiswa anggota ACTIVE. yaitu: kegiatan mengajar, kelas motivasi, belanja bersama anak panti, dan

\section{Culture \& Society: Journal of Anthropological Research Vol. 1, No. 1, Th. 2019}


rekreasi di alam. Di dalam setiap kegiatan tersebut terdapat partisipasi langsung yang dilakukan oleh mahasiswa yang menjadi anggota. Diantaranya menjadi tutor dan kegiatan pengajaran, mengisi kelas motivasi dengan ikut membagi pengalaman inspiratifnya kepada anak-anak panti yang mengikuti kegiatan tersebut. Kemudian juga membantu mengawasi serta membantu mendanai dengan uang kas yang dikumpulkan dari para anggota dalam kegiatan rekreasi dan belanja bersama anak panti asuhan.

\section{Daftar Pustaka}

Ahmad, A. (2009). Psikologi Sosial. Jakarta: Rineka Cipta.

Arikunto. (2006). Prosedur Penelitian Suatu Pendekatan Praktek. Jakarta: Rineka Cipta.

Astuti, W. (2008). Bentuk-bentuk Suatu Partisipasi. Jakarta: Rineka Cipta.

Basir, S. (2011). Soft Skill vs Hard Skill. Jakarta: Kantor Akutansi Publik Syarief Basir dan Rekan.

Basrowi dan Suwandi. (2008). Memahami Penelitian Kualitatif. Jakarta: Rineka Cipta.

Dharmawan Krisna, Aditya. (2016). Faktor-Faktor yang Mempengaruhi Pengungkapan Tanggung Jawab Sosial. Retrieved from http://petra.ac.id

Diani, F. B. (2017). Fenomena Komunikasi Komunitas Kelas Inspirasi (Studi Fenomenologi Social Movement Pada Anggota Komunitas Kelas Inspirasi Pekanbaru). Retrieved from http://medianeliti.com

Dwi Yanika Hesti Nugraha, M. dan Y. N. (2011). Perbedaan Motivasi Intrinsik dan Motivasi Ektrensik Pengurus Himpunan Mahasiswa Jurusan Pada Fakuktas Teknik dan Desain dan Fakultas Ilmu Sosial dan Humaniora Di Universitas Bunda Mulia. Retrieved from http://ubm.ac.id

Emzir. (2010). Metodologi Kualitatif Analisis Data. Raja Grafindo Persada.

Hanurawan, F. (2012). Sikap Mahasiswa Terhadap Penggunaan Diskusi Isu-isu Kontroversial. Retrieved from http://jurnal.um.ac.id

Hakim, Abdul. (2017). Analisis Pengaruh Pembangunan Pasar Sanggam Aji Dilayas Terhadap Sosial Ekonomi Masyarakat Di Kelurahan Gunung Tabur Kabupaten Berau. Retrieved from http://steimtanjunggredeb.ac.id

Humaida, M. dan M. A. (2016). Analisis Gerakan Kerelawan Internasional (Great) of Pekalongan dalam Kegiatan Perpustakaan Sepeda Keliling Pekalongan. Retrieved from http://www.neliti.com

Margono, S. (2004). Metodologi Penelitian Kualitatif. Jakarta: Rineka Cipta.

Muhson, Ali. (2009). Peningkatan Minat Belajar Dan Pemahaman Mahasiswa Melalui Penerapan Problem Based-Learning. Retrieved from http://uny.ac.id

Mustanir, Ahmad. (2018). Partisipasi Masyarakat dan Transect pada Perencanaan Pembangunan. Retrieved from http://reseachgate.net

Nasional, S. P., Pemerintah, P., Tinggi, P., Dasar, U., Nasional, S. P., Tahun, L. N., ... Pemerintah, D. P. (1990). Peraturan Pemerintah Republik Indonesia Tentang Pendidikan Tinggi Presiden Republik Indonesia, Memutuskan : Ketentuan Umum. 152.

Nisfil, L. dan A. I. A. (2015). Altruisme Pada Relawan Perempuan yang Mengajar Anak Berkebutuhan Khusus Di Yayasan Anak Jalanan Bina Insani Mandiri. Retrieved from http://www.neliti.com

Purbathin Hadi, Agus. (2010). Konsep Pemberdayaan, Partisipasi Dan Kelembagaan Dalam Pembangunan. Retrieved from http://50webs.com

Sugiyono. (2012). Metode Penelitian Kualitatif dan Kuantitatif R\&D. Bandung: Alfabeta.

Utami, Muhana. S. (2009). Keterlibatan dalam Kegiatan dan Kesejahteraan Subjektif Mahasiswa. Retrieved from http://journal.ugm.ac.id

Widjajanti, Kesi. (2011). Model Pemberdayaan Masyarakat. Retrieved from http://ums.ac.id

Yusuf, M. (2014). Metode Penelitian kualitatif dan Penelitian Gabungan. Jakarta: Prenadamedia Group. 